Gut, 1971, 12, 123-125

\title{
The effect of nitrogen mustard intoxication on glucose absorption from the small intestine of the rat
}

\author{
M. J. LEIBOWITZ AND P. C. MERKER \\ From the College of Pharmaceutical Sciences, Columbia University, New York, USA
}

SUMMARY Methyl bis ( $\beta$-chlorethyl) amine $\left(\mathrm{HN}_{2}\right)$ was administered as a single intraperitoneal dose to male Sprague-Dawley rats. Animals were given either a median lethal dose and perfused one day after treatment or were given a larger dose and perfused two days after treatment. Intestinal segments were perfused in vivo and samples of effluent were collected and measured for glucose using the glucose oxidase method.

Animals treated with the larger dose of $\mathrm{HN}_{2}$ displayed significant reduction in intestinal dry weight. The average water content of intestinal segments derived from treated animals did not differ significantly from that in controls.

Steady-state glucose absorption, obtained from data collected during the last 40 minutes of the perfusion period, was found to be significantly reduced in animals treated with drugs when intestinal absorption for control and treated animals was adjusted for water movement but not for dry intestinal weight and length. However, when glucose absorption was adjusted for dry tissue mass and length as well as for water movement, no significant differences in intestinal glucose absorption between control and treated rats were observed. Alterations can therefore be attributed to loss of intestinal tissue rather than to loss in the ability of the intestinal mass to absorb glucose.

Cytotoxic agents such as $x$-irradiation (Quastler and Hampton, 1962; Patt and Quastler, 1963; Levin, 1966), amethopterin (Robinson, Antonioli, and Vannotti, 1966), actinomycin D (Yamada, Clark, and Swendseid, 1967), and nitrogen mustard (Sternberg, Philips, and Scholler, 1958; Hampton, 1967) have been shown to cause various morphological changes in the mucosal epithelium of the small intestine. Included in these changes are a decrease or abolition of mitosis in the germinative crypts, decrease in height of the villi, and desquamation of the mucosal surface.

In spite of morphological changes, not all cytotoxic agents have caused alteration in the functional capacity of the small intestine to transport glucose and amino acids. A notable example is the observation of Robinson and his coworkers (1966) who reported that rat intestine damaged by amethopterin retained a considerable capacity for active transport of L-phenylalanine. On the other hand, Yamada and his associates (1967) reported that actinomycin D depressed amino acid transport, but caused small increases in glucose absorption. It is clear, therefore, that the correlation between altered morphology and the state of functional viability of the absorptive Received for publication 7 October 1970. epithelium has not been established. The present investigation was designed to study again the effects of single doses of nitrogen mustard on glucose absorption in vivo by the rat small intestine, with the ultimate intent of performing comparative investigations using a series of antineoplastic alkylating agents. Initial data revealed an interesting relationship between the effects of nitrogen mustard on intestinal weight and glucose absorption. These initial observations are reported in the present paper.

\section{Methods}

Methyl bis ( $\beta$-chloroethyl) amine (nitrogen mustard, $\mathrm{HN}_{2}$ ) was freshly prepared in $0.86 \%$ saline, and administered as a single dose to male SpragueDawley rats weighing 200-350 g each. Rats were given either a median lethal dose, $2 \mathrm{mg} / \mathrm{kg}$, and perfused one day after treatment, or were given $6 \mathrm{mg} / \mathrm{kg}$ and perfused two days after treatment.

Before perfusion the rats were lightly anaesthetized with sodium pentobarbital ( $30-35 \mathrm{mg} / \mathrm{kg})$. One polyethylene cannula was introduced slightly distal to the bile duct and a second cannula was inserted approximately two intestinal loops away from the ileal-caecal junction. The intestinal segment was 
washed with Krebs-Hensleit solution. After the intestinal contents were expelled the intestinal loop was perfused with either 50,100 , or $400 \mathrm{mg} \%$ glucose in a Krebs-Hensleit solution containing $4 \mathrm{mg} \%$ phenol red. Perfusion was carried out at the rate of $1.2 \mathrm{ml} / \mathrm{min}$ for 80 minutes using a Harvard perfusion pump. Samples of the effluent were collected for intervals of five, 10, or 15 minutes during the entire perfusion period.

Glucose was measured by the glucose oxidase method (Beach and Turner, 1958) and phenol red was determined using the method of Schanker, Tocco, Brodie, and Hogben (1958). Glucose absorption was calculated from data derived during the steady-state period, ie, during the 40 -minute period following the start of perfusion. After the perfusion period the intestinal segment was removed, measured, weighed, and then dried at $80^{\circ} \mathrm{C}$ for 24 hours. After drying, the intestine was reweighed and the rate of glucose absorption was calculated in terms of dry intestine weight and length $(\mu \mathrm{g} / \mathrm{mg} / \mathrm{cm} / \mathrm{min})$.

\section{Results}

Gross examination of the abdominal cavity of intoxicated rats revealed thin and flaccid intestines,

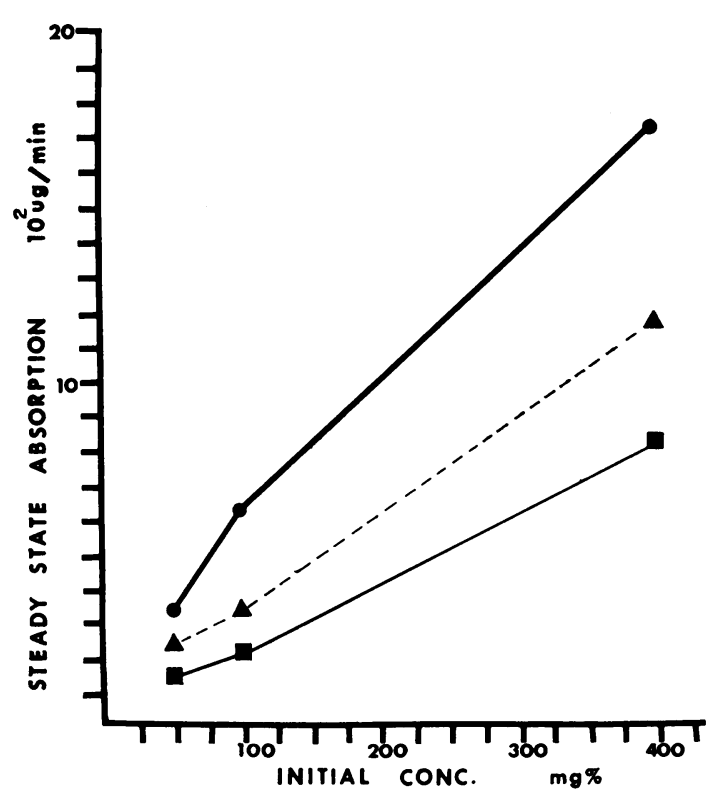

Fig. 1. Effect of nitrogen mustard $\left(\mathrm{HN}_{2}\right)$ treatment on glucose absorption in vivo when glucose absorption is only adjusted for water transfer.

= controls: $\mathbf{A}=$ one day after treatment with $\mathrm{HN}_{2}(2 \mathrm{mg} / \mathrm{kg}) ; \square=$ two days after treatment with $\mathrm{HN}_{2}(6 \mathrm{mg} / \mathrm{kg})$. haemorrhagic and dilated mesenteric blood vessels, and haemorrhagic ascites fluid. Animals treated with drugs displayed reductions in both wet and dry intestinal weight, but a statistically significant reduction in dry weight was only associated with animals treated at $6 \mathrm{mg} / \mathrm{kg}$ and examined two days after the single injection of drug (Table I). Average water content, calculated from data shown in Table I, for treated animals was found to be $84-86 \%$, a value not significantly different from controls.

\begin{tabular}{lccc}
\hline Group & $\begin{array}{l}\text { No. of } \\
\text { Rats }\end{array}$ & $\begin{array}{l}\text { Wet Weight } \\
(\mathrm{mg} / \mathrm{cm})\end{array}$ & $\begin{array}{l}\text { Dry Weight } \\
(\mathrm{mg} / \mathrm{cm})^{\mathrm{2}}\end{array}$ \\
\hline Control & 17 & $100.0 \pm 0.9^{2}$ & $15.4 \pm 2.6$ \\
Treated with $2 \mathrm{mg} / \mathrm{kg}$ & $7^{3}$ & $72.2 \pm 1.95$ & $10.3 \pm 3.5$ \\
Treated with $6 \mathrm{mg} / \mathrm{kg}$ & $20^{4}$ & $50.6 \pm 1.45^{5}$ & $7.7 \pm 1.6^{5}$ \\
\hline
\end{tabular}

Table I Effect of nitrogen mustard treatment, administered as a single intraperitoneal injection, on wet and dry intestinal weight

${ }^{1}$ Dried at $80^{\circ} \mathrm{C}$ for 24 hours.

'Mean \pm SEM.

${ }^{8}$ Sacrificed 24 hours after treatment.

'Sacrificed 48 hours after treatment.

sStatistically different from the control group $(P \leqslant 0.05)$.

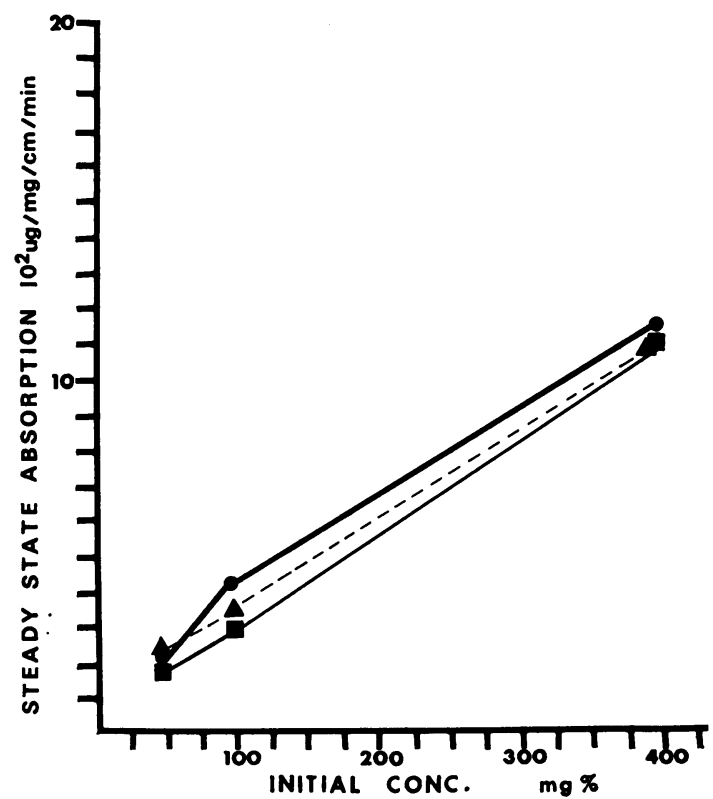

Fig. 2. Effect of nitrogen mustard $\left(\mathrm{HN}_{2}\right)$ treatment on glucose absorption in vivo when glucose absorption is adjusted for water transfer and intestinal weight and length $(\mathrm{mg} / \mathrm{cm})$.

Key as in Figure 1. 
In Fig 1 steady-rate glucose absorption for control and treated groups adjusted for water movement but not dry intestinal tissue weight and length is presented in relation to increasing glucose perfusion concentrations. There is a significant decrease $(P \leqslant 0.05)$ in absorption of glucose between controls and the rats perfused with $\mathrm{HN}_{2}$ two days after treatment.

In Fig. 2 steady-state glucose absorption, adjusted for dry tissue mass and length as well as for water movement, was plotted against initial glucose perfusion concentrations. Under these conditions, it was found that differences in intestinal glucose absorption between the control animals and the rats treated with $6 \mathrm{mg} / \mathrm{kg} \mathrm{HN}$ were not significant $(P \leqslant 0.05)$.

\section{Discussion}

Intoxicated animals treated with nitrogen mustard were shown to have had a significant reduction in intestinal weight. These observations are similar to those reported by McFadyen and Baker (1968) who found that intestinal weights of rats were reduced by approximately $55-70 \%$ one to two days after they had been exposed to $800 \mathrm{rad} x$-irradiation. In the present study, intestinal water content was found to range from $85 \%$ for controls to $84 \%$ for the group of rats perfused two days after treatment. Therefore, loss in intestinal weight cannot be ascribed to changes in water content. In spite of the significantly reduced amount of intestine found in rats treated with $6 \mathrm{mg} / \mathrm{kg} \mathrm{HN_{2 }}$, glucose absorption was found not to be significantly changed. Thus, the simple expedient of adjusting glucose absorption for tissue weight and length was sufficient to account for the decrease in the ability of the animal intoxicated with $\mathrm{HN}_{2}$ to absorb glucose. Additional support for retention of the functional integrity of intestines derived from treated rats lies in the observation that time to 'steady state' for glucose absorption was essentially the same ( 30 minutes) for intoxicated and control animals.

Reduction in glucose absorption by colchicine, as reported by Levin (1966), was found to be significant only for experiments in vivo while experiments in vitro showed no significant difference in absorption between control and treated groups. Examination of Levin's data (1966) reveals that the small intestines of the treated rats were markedly reduced in mass from those of control animals, but glucose absorption was not adjusted for these differences, whereas the intestinal sacs prepared for use in the experi- ments in vitro were of almost equal weight for both treated and control groups. In contrast to the results reported here, amethopterin brings about villous destruction considerably greater than does nitrogen mustard, and as shown by Robinson et al (1966), also suppresses absorption even when tissue weight changes are considered. It has been claimed by Bond (1963) that malabsorption of glucose caused by excessive radiation is not secondary to the tissue damage but is due to a direct effect on the absorptive mechanism, which is conspicuous before any morphological alterations can be detected. Robinson and his coworkers (1966) point out that this is not the case following the administration of antimitotic drugs such as amethopterin, for which reduction in absorption occurs only after there is extensive structural damage.

In our present study with nitrogen mustard we have found that alterations in the absorption of glucose by the whole rat can be attributed to loss of tissue mass. The intestinal tissue remaining after acute $\mathrm{HN}_{2}$ treatment apparently retains the ability to transport glucose to essentially the same extent as normal intestinal tissue.

Abstracted in part from a thesis submitted by M. J. Leibowitz to the College of Pharmaceutical Sciences, Columbia University, in partial fulfilment of the requirements for the MSc degree.

\section{References}

Beach, E. F., and Turner, J. J. (1958). An enzymatic method for glucose determination in body fluids. Clin. Chem., 4, 462-475.

Bond, V. P. (1963). Effects of radiation on intestinal absorption. Amer. J. clin. Nutr., 12, 194-204.

Hampton, J. C. (1967). Effects of nitrogen mustard on the intestinal epithelium. Radiat. Res., 30, 576-589.

Levin, R. J. (1966). Effects of colchicine on intestinal function in the rat. Gut, 7, 250-257.

McFadyen, D. M., and Baker, D. G. (1968). Lyosome activity in radiation induced intestinal injury. In Gastrointestinal Radiation Injury, edited by M. F. Sullivan, pp. 401-412. Excerpta Medica Foundation, Amsterdam.

Patt, H. M., and Quastler, H. (1963). Radiation effects on cell renewal and related systems. Physiol. Rev., 43, 357-396.

Quastler, H., and Hampton, J. C. (1962). Effects of ionizing radiation on the fine structure and function of the intestinal epithelium of the mouse. I. Villus epithelium. Radiat. Res., 17, 914-931.

Robinson, J. W. L., Antonioli, J. A., and Vannotti, A. (1966) Effect of oral methotrexate on the rat intestine. Biochem. Pharmacol., 15, 1479-1489.

Schanker, L. S., Tocco, D. J., Brodie, B. B., and Hogben, C. A. M. (1958). Absorption of drugs from the rat small intestine. $J$. Pharmacol. exp. Ther., 123, 81-88.

Sternberg, S., Philips, F. S., and Schollo, J. (1958), The pharmacological and pathological effects of alkylating agents. Annal. N.Y. Acad. Sci., 68, 811-825.

Yamada, C., Clark, A. J., and Swendseid, M. E. (1967). Actinomycin $D$ effect on amino ac:d absorption $f$. om rat jejunal loops. Science, 158, 129-130. 